\title{
Clinical Workflow Considerations for Implementation of Continuous-Bed-Motion PET/CT
}

\author{
Shelley N. Acuff and Dustin Osborne \\ Department of Radiology, University of Tennessee Graduate School of Medicine, University of Tennessee Medical Center, \\ Knoxville, Tennessee
}

\begin{abstract}
CE credit: For CE credit, you can access the test for this article, as well as additional JNMT CE tests, online at https://www.snmmilearningcenter.org. Complete the test online no later than December 2019. Your online test will be scored immediately. You may make 3 attempts to pass the test and must answer $80 \%$ of the questions correctly to receive $1.0 \mathrm{CEH}$ (Continuing Education Hour) credit. SNMMI members will have their CEH credit added to their VOICE transcript automatically; nonmembers will be able to print out a CE certificate upon successfully completing the test. The online test is free to SNMMI members; nonmembers must pay $\$ 15.00$ by credit card when logging onto the website to take the test.
\end{abstract}

Within the last $3 \mathrm{y}$, a new type of technology has emerged for PET imaging that uses a continuous-bed-motion (CBM) acquisition. For technologists, this type of acquisition requires some modifications of the standard approach to PET protocols and imaging workflows. There are several key aspects of CBM that technologists need to learn and understand when transitioning from traditional step-and-shoot PET imaging to this new technology, including differences in acquisition type, image quality, and protocol setup as well as the impact that CBM can have on workflow. This article explains how CBM differs from step and shoot and focuses on the issues critical for technologists to know when first using this technology.

Key Words: CBM; PET; gating; continuous bed motion

J Nucl Med Technol 2016; 44:55-58

DOI: 10.2967/jnmt.116.172171

\section{O}

nce the development of PET, data have always been collected using the same type of whole-body acquisition method, known as step and shoot (SS). Another PET acquisition method, known as continuous bed motion (CBM), was described by Dahlbom et al. in 2000 and tested on a clinical lutetium oxyorthosilicate platform by Brasse et al. in 2002 $(1,2)$. Within the last $2 \mathrm{y}$, this technology has become clinically available for commercial PET/CT systems. In addition to changing typical clinical workflows, this new technology introduces a few important changes in scanner operation. This work provides insight into using CBM technology and compares this technology with standard SS techniques. All studies at our facility were performed under the approval of the University of Tennessee Institutional Review Board (3640, 3539, 3731).

\footnotetext{
Received Jan. 13, 2016; revision accepted Feb. 22, 2016.

For correspondence or reprints contact: Shelley Acuff, MITRP, 1924 Alcoa Hwy., Knoxville, TN 37920.

E-mail: sacuff@utmck.edu

Published online Apr. 21, 2016.

COPYRIGHT (C) 2016 by the Society of Nuclear Medicine and Molecular Imaging, Inc.
}

\section{LEARNING OBJECTIVES}

Readers will be able to understand and describe important differences between standard PET and CBM PET technologies, describe the advantages of CBM PET, and translate standard PET protocols into CBM variations.

\section{NOVELTY OF CBM}

CBM technology requires that technologists have a slightly different way of thinking in completing a scan. The term bed position, referring to a single field of view (FOV), is not used unless the scanner is configured for traditional acquisition methods. Like CT, for CBM PET all that matters in designating the scan length is the desired axial range or ranges to be configured for the acquisition. In the current implementation of clinical CBM technology, a technologist has the option of applying 1-4 different ranges, each allowing different speeds of acquisition through selected parts of the body. For example, for the head and neck axial range, the technologist may select a bed speed different from that chosen for the lower-extremity axial range.

\section{PRIMARY DIFFERENCES BETWEEN SS AND CBM}

There are several differences to consider when transitioning from traditional SS PET imaging to CBM PET imaging. These differences include acquisition type, image quality, and protocol setup.

\section{Acquisition Type}

The most obvious difference between SS and CBM is the way the bed moves during the acquisition. Traditionally, with an SStype scanner the table pauses for the time selected for a bed position and then moves suddenly to the next bed position; this is where the name step and shoot is derived. Then, the bed positions are stitched together to form a whole-body image. During wholebody PET acquisitions using CBM, the table is in continuous motion from the beginning to the end of the selected axial range.

\section{Image Quality}

Although SS and CBM differ most significantly in workflow, protocol design, and scanner operation, there are slight 
differences in image quality and quantification that are useful to understand in determining appropriate imaging parameters. Over the past $3 \mathrm{y}$, several publications have characterized the performance of CBM PET/CT in relation to traditional acquisition methods. Each of these papers had different approaches but reported similar results and conclusions.

Two of these investigations reviewed the clinical quantitative performance of CBM versus SS and reported no statistically significant differences in measured SUVs or visual interpretation of image data between the 2 technologies $(3,4)$. A third publication showed that key National Electrical Manufacturers Association performance and image quality parameters did not vary significantly between the 2 technologies (5). These studies provide evidence that imaging facilities can easily change between these 2 modes of acquisition without any need for corrections.

Comparisons of patient preference between SS and CBM indicated a strong preference for CBM, which was found to be more relaxing, quieter, and more fluid than scanning performed with SS technology (3). When masked to the data-acquisition method, physicians also showed a slight preference toward data acquired using CBM technique, in comparison with SS technique (4). This preference might be attributable to the improvement in end-plane imaging using CBM technique, as shown by both Osborne et al. and Rausch et al. in their independent studies $(4,5)$. In both studies, end planes using CBM technique were shown to have statistically significant improvements in image quality and quantitation.

\section{Protocol Setup}

The protocol setup differs somewhat between SS and CBM, in turn requiring slight differences in the way the technologist must think about imaging the patient. In traditional SS imaging, the number of minutes per bed position and the total number of bed positions required to cover the desired axial range are used to determine the total scan time. With $\mathrm{CBM}$, only bed speed $(\mathrm{mm} / \mathrm{s})$ and axial range are used to determine scan time. If more counts are needed with SS imaging, the technologist increases the number of minutes per bed position, but with CBM the inverse is true and bed speed is decreased to increase the number of counts in the acquisition. This concept is similar to setting up a nuclear medicine bone scan. There is also the potential for time savings when setting up protocols using CBM technique. Being able to use ranges instead of individual bed positions saves the technologist time by decreasing the number of mouse clicks involved and enables optimization of the exact ranges required to cover a given anatomic region (6).

The most important improvement for a technologist is being able to set the FOV with CT-like ranges, obviating individual PET bed positions. Many times, a technologist is faced with needing slightly more coverage for the PET FOV and is forced to add a complete bed position to the acquisition protocol. This additional position adds scan time and results in extra radiation exposure from having to extend the CT range to match the PET FOV. When setting up a CBM PET/CT examination, the technologist is now able to select the exact ranges desired for both CT and PET FOVs, resulting in an optimized scan time and an average $5 \%$ CT dose reduction for the patient (4).

\section{IMPACT ON WORKFLOW}

CBM technology improves several aspects of the imaging workflow: the standard scan time, the time to set up complex protocols, and the time to acquire gated scans. Almost every capability of CBM is also possible with SS, but with the latter requiring more scan and setup time (4).

\section{CBM Enables Exact Range Selection}

Standard Whole-Body PET Protocols. For standard wholebody PET protocols, the ability of CBM to allow selection of the exact axial PET range has the largest impact on workflow, potentially lowering the $\mathrm{CT}$ dose to the patient, reducing time on the scanner, and decreasing overall patient motion. Faster workflows may also improve imaging efficiency by optimizing scheduling and may improve the experience of patients by minimizing their time on the scanner.

Melanoma Protocols. The biggest influence CBM has on a melanoma protocol is the capability of selecting multiple ranges with independent bed speed settings. The setup time using SS can take longer for a melanoma protocol than for other protocols because of the large number of bed positions needed to complete the scan. In melanoma PET, the imaging time for the lower extremities is commonly reduced, resulting in a decreased time per bed position in traditional SS imaging and an increased bed speed in CBM imaging (7).

TABLE 1

Our Institution's Protocol Settings for Gating

\begin{tabular}{|c|c|c|c|c|}
\hline Protocol & Range 1 & Range 2 & Range 3 & Range 4 \\
\hline Standard whole-body & $\begin{array}{l}1.5 \mathrm{~mm} / \mathrm{s} \text { (eyes through } \\
\text { thighs) }\end{array}$ & & & \\
\hline Melanoma & $\begin{array}{l}1.5 \mathrm{~mm} / \mathrm{s} \text { (eyes through } \\
\text { thighs) }\end{array}$ & $\begin{array}{l}2 \mathrm{~mm} / \mathrm{s} \text { (thighs through } \\
\text { toes) }\end{array}$ & & \\
\hline Respiratory gating & $\begin{array}{l}1.5 \mathrm{~mm} / \mathrm{s} \text { (eyes through } \\
\text { lung apex) }\end{array}$ & $\begin{array}{l}0.4 \mathrm{~mm} / \mathrm{s} \text { (lung apex } \\
\text { through lung base) }\end{array}$ & $\begin{array}{l}1.5 \mathrm{~mm} / \mathrm{s} \text { (lung base } \\
\text { through thighs) }\end{array}$ & \\
\hline $\begin{array}{l}\text { High-resolution combination } \\
\text { scan (high-resolution head, } \\
\text { gated lung) }\end{array}$ & $\begin{array}{l}0.5 \mathrm{~mm} / \mathrm{s} \text { (skull top } \\
\text { through skull base) }\end{array}$ & $\begin{array}{l}1.5 \mathrm{~mm} / \mathrm{s} \text { (skull base } \\
\text { through lung apex) }\end{array}$ & $\begin{array}{l}0.4 \mathrm{~mm} / \mathrm{s} \text { (lung apex } \\
\text { through lung base) }\end{array}$ & $\begin{array}{l}1.5 \mathrm{~mm} / \mathrm{s} \text { (lung base } \\
\text { through thighs) }\end{array}$ \\
\hline
\end{tabular}




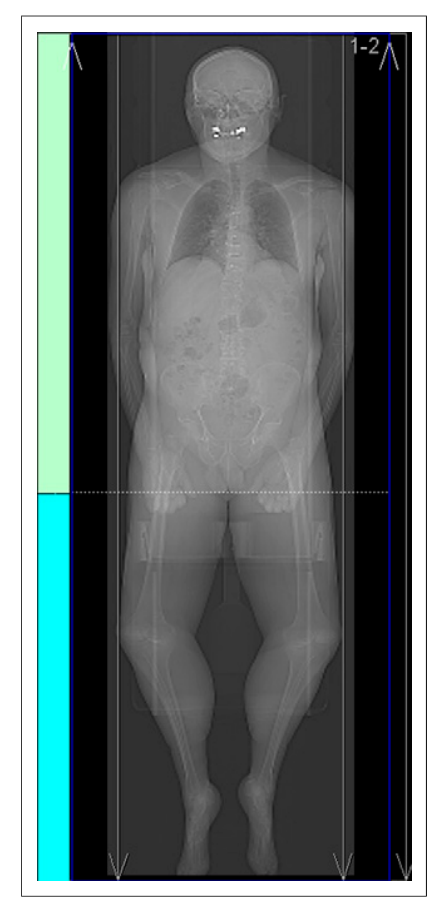

FIGURE 1. PET/CT melanoma protocol that has been set up using 2 CBM ranges.
Current clinical implementations of CBM have multiple selectable ranges, enabling use of one range to scan the head through the pelvis at a normal bed speed and another range to scan the legs at an increased bed speed (Table 1). To set up this protocol, the technologist would have to set the speed for only 2 ranges instead of for each of the possibly 4 or 5 bed positions-depending on the height of the patientfor a traditional SS protocol. The result is a faster setup time and the potential for an optimized scan time (Fig. 1).

Gating Protocols. At our institution, the use of CBM range selection has improved the efficiency of gating protocols. For example, for most patients a single bed position will not cover the entire lung, but the range covered by 2 full bed positions is excessive, as shown in Figure $2(8)$. The time to gate 2 bed positions over the lungs during a whole-body scan can be almost triple that of a normal whole-body scan $(4,9)$. Most institutions with SS do not gate lung scans because of the time they require $(8,9)$.

CBM permits an exact range to be selected over the lungs, optimizing time and making these protocols feasible for routine clinical use. In comparison with SS gating, CBM gating reduces the total acquisition time by an average of $23 \%$ (9). Before our institution implemented CBM, gated studies were performed only if requested by

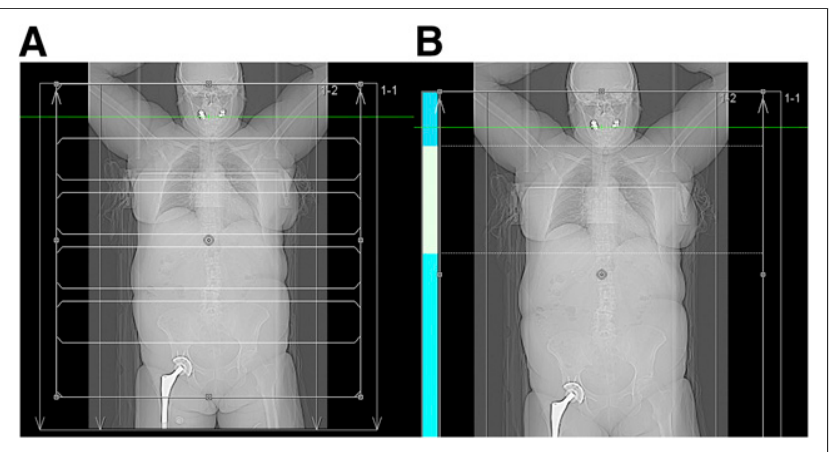

FIGURE 2. Comparison of respiratory gating using SS vs. CBM. (A) Multi-bed-position SS method shows number of positions required to cover lungs. (B) Three-range CBM gating image shows how exact ranges can be set around lung field and the advantage of not being limited by bed size. the referring physician. Since beginning to apply CBM to optimize our workflows, we have been able to offer gated PET imaging whenever respiratory motion might negatively affect the diagnostic quality of images, and we now use it routinely on all imaging involving the lung, pancreas, liver, or stomach. Our protocol settings for gated imaging can be seen in Table 1 .

\section{CBM Enables Complex Protocols}

In PET/CT imaging, there often is a need for highresolution imaging of a specific area of the body, depending on the diagnosis. There also are times when one area of the body requires a high-resolution scan along with a gated scan. SS imaging is able to complete this type of acquisition but at the cost of a significant increase in scan time. Depending on the area, the time to cover 2-3 bed positions would have to be tripled to achieve the desired image quality. The outcome is a lengthy scan that may not be possible for every patient without significantly affecting departmental scheduling. CBM offers the ability to create a complex protocol that selects exact ranges over multiple areas to acquire a single study with high resolution, standard wholebody gating, and fast imaging of the extremities.

For example, a complex protocol for a melanoma patient with lung disease accompanied by brain metastases would include a first range from the top of the head to the apices of the lungs, scanned at $0.5 \mathrm{~mm} / \mathrm{s}$; a second range from the apices to the base of the lungs, scanned at $0.4 \mathrm{~mm} / \mathrm{s}$; a third range from the base of the lungs through the abdomen and pelvis, scanned at $1.5 \mathrm{~mm} / \mathrm{s}$; and a fourth range from the bottom of the pelvis through the lower extremities, scanned at $2 \mathrm{~mm} / \mathrm{s}$ (Fig. 3). The result is that in a single pass and in an optimized time, the physician now has a high-resolution head, motion-corrected lung, and whole-body melanoma scan.

The key with CBM is being able to select the exact axial ranges for the desired areas, instead of being limited to the individual bed sizes of SS. The impact of single bed sizes becomes more pronounced with systems that have small axial FOVs (3-ring vs. 4ring).

\section{Use of CBM for Single-Bed-Position Acquisitions Is Limited}

The time-savings and workflow benefits of CBM in complex PET protocols do not apply to single-bed-position acquisitions. In imaging of topogram.

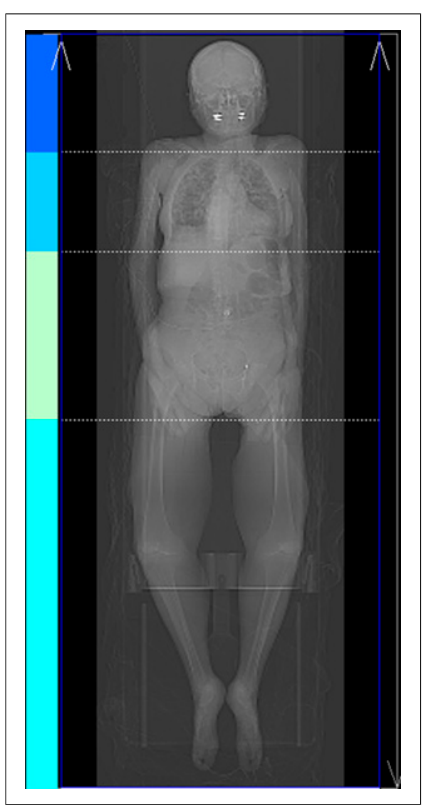

FIGURE 3. Example of complex workflow and ranges set on a 
the brain or liver - or of any limited area that would fit within the size of 1 bed position-there is no need to set exact axial ranges. The smallest range that can be set using CBM protocols is the maximum axial FOV of the PET scanner plus a slight additional overscan amount.

\section{CONCLUSION}

When transitioning from SS PET/CT to CBM PET/CT, technologists need to learn the essential differences between the two, including differences in acquisition technique, image quality, protocol setup, and effect on daily workflow. With these differences come some advantages to using CBM over SS, such as greater efficiency in protocol setup and in gated acquisitions, as well as the ability to complete complex protocols in a single pass and within a time that is highly compatible with everyday clinical use.

\section{DISCLOSURE}

Dustin Osborne and Shelley Acuff occasionally provide expert testimony for Siemens Medical Solutions USA, Inc. The University of Tennessee has ongoing collaborative relationships with Siemens Medical Solutions USA, Inc. No other potential conflict of interest relevant to this article was reported.

\section{ACKNOWLEDGMENT}

We thank Chris Carr RT(R), CNMT, for his assistance in acquiring data and helping support our research efforts at the medical center.

\section{REFERENCES}

1. Dahlbom M, Reed J, Young J. Implementation of true continuous 2D/3D whole body PET scanning. IEEE Nucl Sci Symp Conf Rec. 2000;3:17/13-17/17

2. Brasse D, Newport D, Carney JP, et al. Continuous bed motion acquisition on a whole body combined PET/CT system. IEEE Nucl Sci Symp Conf Rec. 2002;2:951-955.

3. Schatka I, Weiberg D, Reichelt S, et al. A randomized, double-blind, crossover comparison of novel continuous bed motion versus traditional bed position wholebody PET/CT imaging. Eur J Nucl Med Mol Imaging. 2016;43:711-717.

4. Osborne DR, Acuff S, Cruise S, et al. Quantitative and qualitative comparison of continuous bed motion and traditional step and shoot PET/CT. Am J Nucl Med Mol Imaging. 2014;5:56-64.

5. Rausch I, Cal-Gonzalez J, Dapra D, et al. Performance evaluation of the Biograph mCT Flow PET/CT system according to the NEMA NU2-2012 standard. EJNMMI Phys. 2015;2:26.

6. Acuff S, Bradley Y, Stuckey A, Osborne D. Routine PET/CT workflow efficiency and scan time improvements using continuous bed motion (CBM) techniques [abstract]. J Nucl Med. 2015;56(suppl 3):2629.

7. Tyler DS, Onaitis M, Kherani A, et al. Positron emission tomography scanning in malignant melanoma. Cancer. 2000;89:1019-1025.

8. Huang TC, Chou KT, Wang YC, Zhang G. Motion freeze for respiration motion correction in PET/CT: a preliminary investigation with lung cancer patient data. Biomed Res Int. 2014;2014: 167491.

9. Acuff S, Bradley Y, Stuckey A, Osborne D. PET/CT gating workflow efficiency improvements using continuous bed motion imaging techniques [abstract]. $\mathrm{J} \mathrm{Nucl}$ Med. 2015;56(suppl 3):2628. 